\title{
Aligned vertical growth of zinc oxide nanorods on glass substrates using optimum hydrothermal synthesis technique
}

\author{
Mohd Hafiz Jali' ${ }^{1}$, Md Ashadi Md Johari², Hazli Rafis Abdul Rahim ${ }^{3}$, Haziezol Helmi Mohd Yusof ${ }^{4}$, \\ Aminah Ahmad ${ }^{5}$, Mohamad Faizal Baharom ${ }^{6}$, Sulaiman Wadi Harun ${ }^{7}$ \\ ${ }^{1,6}$ Faculty of Electrical Engineering, Universiti Teknikal Malaysia Melaka, Melaka, Malaysia \\ ${ }^{2,5}$ Faculty of Electrical and Electronic Engineering Technology, Universiti Teknikal Malaysia Melaka, Melaka, Malaysia \\ ${ }^{3,4}$ Faculty of Electronic and Computer Engineering, Universiti Teknikal Malaysia Melaka, Melaka, Malaysia \\ ${ }^{7}$ Department of Electrical Engineering, University of Malaya, Kuala Lumpur, Malaysia
}

\begin{tabular}{|c|c|}
\hline Article Info & ABSTRACT \\
\hline Article history: & This paper reported an optimized hydrothermal synthesis technique to grow \\
\hline Received May 15, 2021 & $\begin{array}{l}\text { zinc oxide }(\mathrm{ZnO}) \text { nanorods vertically on the normal microscope glass. } \mathrm{ZnO} \\
\text { nanorods exhibited various advantages such as strong binding energy non }\end{array}$ \\
\hline Revised Jul 6, 2021 & toxicity, large surface to volume ratio and versatility for optical detections. \\
\hline Accepted Jul 7, 2021 & $\begin{array}{l}\text { However, the growth of nanorods which aligned vertically on the glass } \\
\text { substrates is rather complicated. It required a thorough process based on }\end{array}$ \\
\hline Keywords: & $\begin{array}{l}\text { optimized concentration, growth duration, growth temperature and solvent } \\
\text { variations. The morphological structure result has shown an exceptional }\end{array}$ \\
\hline Glass substrate & $\begin{array}{l}\text { vertical growth of the nanorods on the glass surfaces which increase the } \\
\text { nanorods density. The optimized synthesis technique produced high density }\end{array}$ \\
\hline Hydrothermal & $\mathrm{ZnO}$ nanorods up to $3 \times 10^{13}$ nanorods $/ \mathrm{m} 2$ which is double as compared to \\
\hline $\begin{array}{l}\text { Vertical growth } \\
\mathrm{ZnO} \text { nanorods }\end{array}$ & conventional synthesis technique. \\
\hline
\end{tabular}

This is an open access article under the $\underline{C C B Y-S A}$ license.

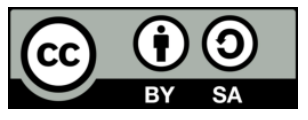

\section{Corresponding Author:}

Mohd Hafiz Jali

Faculty of Electrical Engineering

Universiti Teknikal Malaysia Melaka

Durian Tunggal, Melaka, Malaysia

Email: mohd.hafiz@utem.edu.my

\section{INTRODUCTION}

Zinc oxide $(\mathrm{ZnO})$ nanorods is an essential functional material. At ambient temperature, it has a substantial exciton binding energy $(60 \mathrm{meV})$ and a wide bandgap of $3.4 \mathrm{eV}$. When exposed to the surrounding response, the nanomaterial works as a receptor layer. It causes a change in its optical characteristics, which the evanescent field detects. The optical change is determined by the interaction's affinity constant [1]. One of the many nanostructures of $\mathrm{Zinc}$ oxide $(\mathrm{ZnO})$ that has become a suitable nanomaterial in many applications is single crystalline of $\mathrm{ZnO}$ nanorods. It is a semiconductor material that is frequently employed in a range of integrated nano-systems such as resonators, solar cells, and antenna [2]-[8].

Zinc oxide has hexagonal structure with lattice parameters $a=0.3296$ and $c=0.52065 \mathrm{~nm}$. It is an alternating planes comprised of tetrahedrally coordinated $\mathrm{Zn}^{2+}$ and $\mathrm{O}^{2-}$ ions that stacked alternately along c-axis [9]. Because of its dynamic structure, wide range of morphologies, and surface chemistry, it stands out among other metal oxide semiconductors [10], [11]. Hydrothermal synthesis technique has become preferable synthesis method due to its simple growth condition. It uses alcohol as a medium to expedite the nucleation and growth as compared to water. Furthermore, it is environmental friendly method as it does not required additional organic solvents or procedure such as calcination and grinding [12]. Hydrothermal 
synthesis technique exhibits several benefits such as simple technique, low temperature (between $60-100^{\circ} \mathrm{C}$ ), high yield and more controllable process. The crystal could growth in diverse dimensions and shapes which relied on the composition of starting mixture, process temperature and pressure. Thus it provides high purity material with high degree of crystallinity [13]. This method is based on solution phase synthesis, which can be done in an aqueous solution at temperatures lower than the boiling point of water. Because of its simplicity, tolerable growth conditions and low cost, it is a preferred synthesis approach over gaseous phase synthesis [14].

Extensive research on growing $\mathrm{ZnO}$ nanorods on different platforms, including glass substrates, aluminium foil, plastic optic fibre, and silica microfiber, has been proven. It's also been shown on flexible platforms including PEN substrates, paper substrates, polyimide substrates and ITO/PET substrates. Despite numbers of nanostructures such as nanoflowers, nanospheres and nanowires have been introduced, one dimensional (1-D) nanorods have a specific attribute for sensing application such as reducing the electronhole pair recombination possibilities, direct charge transport along with $\mathrm{ZnO}$ arrays, higher surface-tovolume ratio and chemically reactive surface [15]. Furthermore, high concentrations of oxygen vacancies allow many active sites for molecules adsorption [16]. However, the problem of producing optimum nanorods physical structure which vertically growth is it required thorough and precise procedure. There were numerous studies on improving the $\mathrm{ZnO}$ nanostructures growth by optimization of the synthesis process such as concentration alterations [17], [18], growth duration [19], growth temperature [20] and solvent variations [21]. Growth duration is one of the most important parameters because it influences the nanorods dimension such as density, length and optical scattering cross section. These dimensions could change the optical response of the nanostructures in term of attenuation coefficients and scattering [22].

This paper would explain comprehensive step by step hydrothermal synthesis process in order to produce well aligned vertical growth direction of $\mathrm{ZnO}$ nanorods on the glass substrates based on the most optimal parameters found in the literature. It is start with the elaboration of the optimum synthesis parameters for the $\mathrm{ZnO}$ nanorods growth, following by the results and discuccion and eventually the conclusion.

\section{OPTIMUM GROWTH OF ZNO NANORODS VIA HYDROTHERMAL METHOD ON GLASS SUBSTRATES}

Hydrothermal synthesis process was employed for $\mathrm{ZnO}$ nanorods coating onto microscope glass (Heathrow Scientific LLC, USA). The synthesis process required three major steps which are glass substrate preparation, seeding and growth process.

\subsection{Preparation og glass substrate}

For the ultrasonic cleaning procedure, standard microscope glass substrates (Heathrow Scientific LLC, USA) were submerged in a container of soap water for 15 minutes. The soap water was then dumped, and the washing procedure was resumed with pure water for another 15 minutes. The glass substrates were then submerged in acetone [CH3COCH3] (Bendosen Laboratory Chemical, Germany) using water bath process for 15 minutes before being put in an oven at $90{ }^{\circ} \mathrm{C}$ for 1 hour to remove organic material. Figure 1 summarises the preparation method.

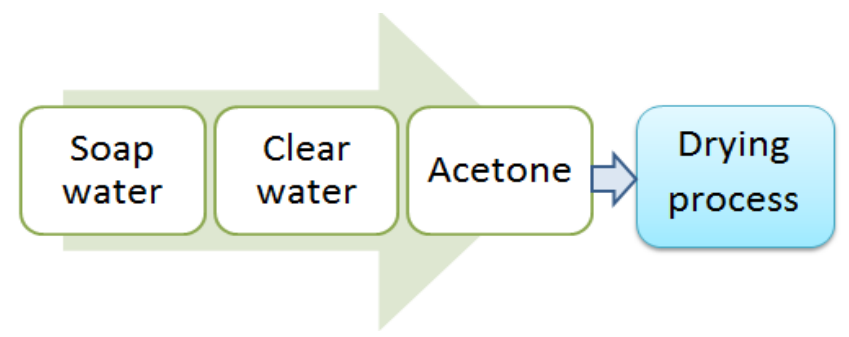

Figure 1. Glass substrates preparation process

\subsection{Seeding process}

Figure 2 shows the seeding procedure, which was carried out on the glass substrates. This is this to create nucleation centers for $\mathrm{ZnO}$ nanorods growth. The uniformity, diameter, length and density of the $\mathrm{ZnO}$ nanorods are highly reliance to this procedure. It involves three main steps which are seeding solution preparation, forming nucleation centers on glass substrates and annealing. 


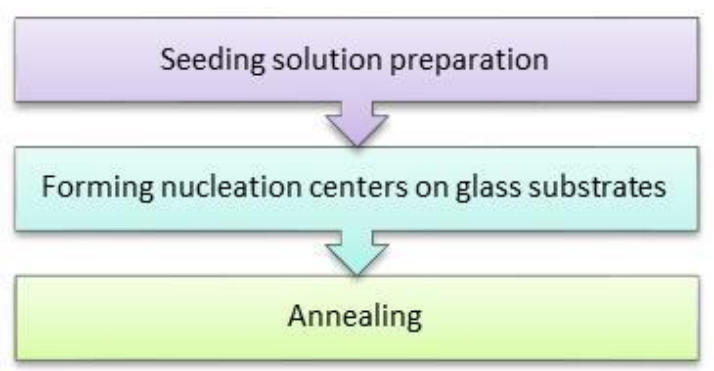

Figure 2. Seeding procedure on the glass substrates

Initially, two set of solutions were prepared which are $\mathrm{ZnO}$ nanoparticles solution and $\mathrm{pH}$ control solution. The first solution was synthesized by adding zinc acetate dehydrate $\left[\mathrm{Zn}\left(\mathrm{O}_{2} \mathrm{CCH}_{3}\right)_{2} \cdot 2 \mathrm{H}_{2} \mathrm{O}\right]$ (Friendemann Schmidt, Germany) in ethanol $\left[\mathrm{C}_{2} \mathrm{H}_{5} \mathrm{OH}\right]$ (HmbG Chemical, Germany) under continuous stirring at temperature of $60{ }^{\circ} \mathrm{C}$ for 30 minutes. After the mixture was cooled down to the ambient temperature, the solution was then further diluted by adding another $60 \mathrm{ml}$ of pure ethanol slowly to produce $120 \mathrm{ml}$ uniform $\mathrm{ZnO}$ nanoparticle solution as shown in Figure 3. Ethanol is capable to expedite the nucleation and growth rate of the nanorods as compared to water.

For $\mathrm{pH}$ control solution, aliquots of $0.003 \mathrm{~g}$ of sodium hydroxide pellets $[\mathrm{NaOH}$ ] (Friendemann Schmidt Chemical, Germany) was added into $60 \mathrm{ml}$ of pure ethanol under continuous stirring at temperature of $60{ }^{\circ} \mathrm{C}$ for 30 minutes as shown in Figure 4. This control solution is essential to determine the $\mathrm{ZnO}$ properties via hydrothermal process. The growth of the nanorods will improve when the $\mathrm{pH}$ of the $\mathrm{ZnO}$ nanoparticles solution increase to alkaline. The $\mathrm{pH}$ value could affect the nuclei and environment of the $\mathrm{ZnO}$ growth [23].

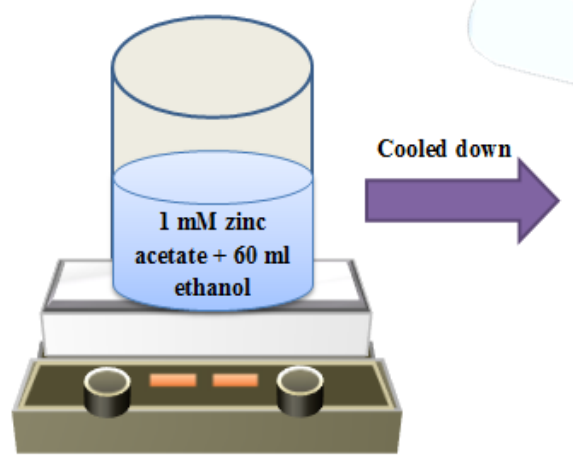

Stirring at $60^{\circ} \mathrm{C}$ for 30 minutes

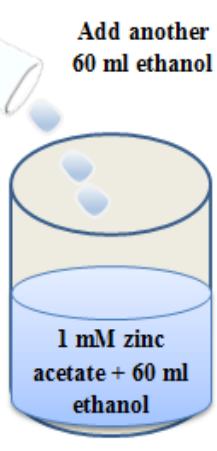

Figure 4. Preparation of the $\mathrm{pH}$ control solution

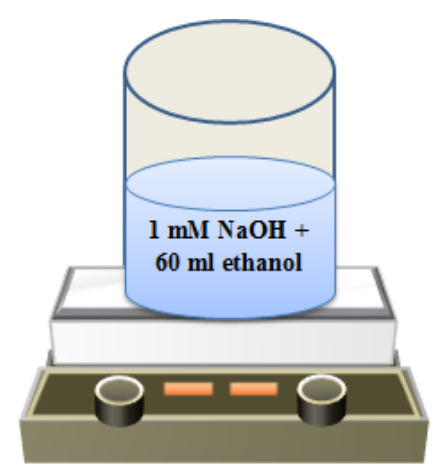

Figure 3. Preparation of the $\mathrm{ZnO}$ nanoparticles solution

The $\mathrm{pH}$ control solution was included into $\mathrm{ZnO}$ nanoparticles solution after 10 minutes. It was conducted by using drop and stir technique where the $\mathrm{ZnO}$ nanoparticles solution was stirred for every single $1 \mathrm{ml} \mathrm{pH}$ control solution drop using pipet for around 1 minute as shown in Figure 5. This process was repeated until the $\mathrm{pH}$ increases from $\sim 4$ to $\sim 9$. This step is crucial to provide more hydroxyl ions $\left(\mathrm{OH}^{-}\right)$[14]. The combination was then placed in a water bath at $60{ }^{\circ} \mathrm{C}$ for 3 hours, or until the colour of the solution changed from clear to milky.

Figure 6 shows the procedure of forming nucleation sites on the glass substrates. Firstly, the glass substrates were placed on a hot plate at a fixed temperature of $70{ }^{\circ} \mathrm{C}$. $\mathrm{ZnO}$ nanorods were grown on the cleaned glass surfaces. An amount of $1 \mathrm{ml}$ of the seeding solution was drop on the glass substrates by using a pipette. Drop and dry technique was used because it is the most effective seeding method. To ensure that the seeds were properly adhered, the solvent was allowed to evaporate for 5 minutes. To ensure optimal seed dispersion on the surface of glass substrates, the technique was repeated ten times. The samples were then annealed for 3 hours at $300{ }^{\circ} \mathrm{C}$. 


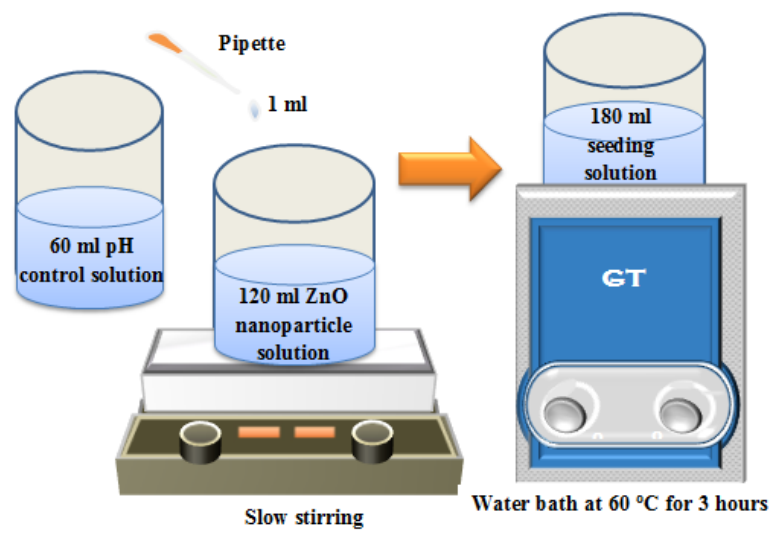

Figure 5. Drop and stir technique for alkaline process to prepare seeding solution

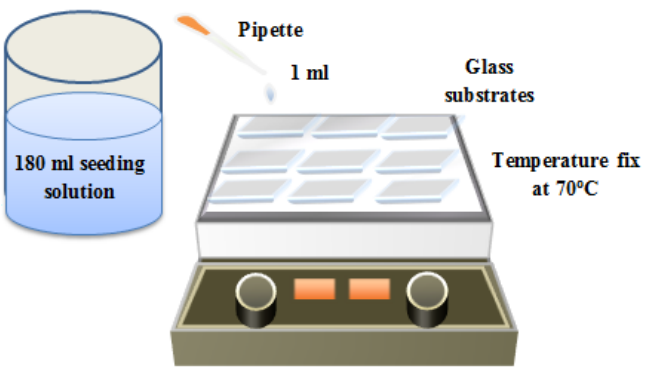

Figure 6. Drop and dry technique on the glass substrates

\subsection{Growth process}

$\mathrm{ZnO}$ growth was performed after the seeding process completed. At first the growth solution was prepared as shown in Figure 7. A $1.4875 \mathrm{~g}$ zinc nitrate hexahydrate [ $\mathrm{Zn}(\mathrm{NO} 3) 2 \cdot 6 \mathrm{H} 2 \mathrm{O}]$ (Sigma-Aldrich) and $0.7 \mathrm{~g}$ of hexamethyleneteramine or HMT [(CH 2)6N4] (Sigma-Aldrich) were dissolved in $500 \mathrm{~mL}$ of deionized (DI) water and stirred for 10 minutes. Zinc Nitrate Hexahydrate $\mathrm{Zn}\left(\mathrm{NO}_{2}\right)_{3}$ has been used as an aqueous solution for hydrothermal synthesis of $\mathrm{ZnO}$ nanorods growth as reported in the literature [24]. It acts as a source of $\mathrm{Zn}^{2+}$ ions when the growth was conducted in a temperature range between 100 to $150{ }^{\circ} \mathrm{C}$. It was reported that $\mathrm{ZnO}$ powder is nucleated in a heterogeneous system and zinc hydroxide precursors would dissolve partially at $\mathrm{pH}$ level less than 11 . While at $\mathrm{pH}$ level more than 11 , the zinc hydroxide precursors are wholly dissolved to form a clear solution. HMT that acts as surfactant play a significant role in modification of $\mathrm{ZnO}$ particles. There are another two important variables in $\mathrm{ZnO}$ nanorods preparation via hydrothermal technique which are temperature and time. It was reported that the $\mathrm{ZnO}$ particles increase as the HMT concentrations, process time and temperature rise [25]. HMT not only provide hydroxyl ions to generate the precipitation reaction but also represent as a buffer when the hydrolysis rate reduced with increasing $\mathrm{pH}$ increases and vice versa. Other literature described the function of HMT in different perspective [26]. It has been mentioned that the HMT would attach to the non-polar facets of zincite crystal to produce a long chain polymer and a non-polar chelating agent. This avoids the excess of $\mathrm{Zn}^{2+}$ ions that resulted in only the side of polar (0001) leave for epitaxial growth. Thus, HMT would play a role as a shape inducing polymer surfactant rather than as a buffer as described earlier. Therefore, the $\mathrm{ZnO}$ morphologies could be controlled by altering the amount of $\mathrm{pH}$, soft surfactant and ethylenediamine of the mixture of sodium hydroxide, zinc acetate and surfactant. Homogeneous growth achieved at $\mathrm{pH}$ of 12 and it becomes inhomogeneous when the $\mathrm{pH}$ level decreased. It was reported that the sample with 1:1 molar ratio of the precursor exhibits the highest photocatalytic efficiency. It was also found that 1:1 molar ratio of zinc nitrate and HMT produce good quality nanorods [18].

Prior of the growth procedure on the glass substrates, the setup for the stage of the samples needs to be prepared. The purpose of the stage is to ensure a gap between the seeded area of the glass substrates and the bottom surface of the petri dish. Eventually the seeded glasses were placed on the stages inside the petri dish with the seeded area were positioned facing downwards to the bottom of the petri dish as shown in Figure 8(a). After that, the seeded glass substrates were submerged in $200 \mathrm{ml}$ of the solution and cooked in a $90{ }^{\circ} \mathrm{C}$ oven in a Figure 8(b) and (c). To maintain a consistent growth rate, the synthesis solution was changed every 5 hours. The $\mathrm{ZnO}$ nanorods were developed for 12 hours in the experiment. The $12 \mathrm{~h}$ growth time was chosen because it increases the numbers of nanorods density as compared to the other growth hour sample which allow maximum light scattering and limit the backscattering which enhanced the coupling efficiency. The growth procedure was completed by extracting the samples and washing them in DI water several times. Figure 8 depicts the coated glass with $\mathrm{ZnO}$ nanorods (Figure $8(\mathrm{~d})$ ). Due to the quicker thermal breakdown of hexamine and the release of more $\mathrm{OH}^{-}$at high temperatures, the synthesis temperature impacts the growth rate of $\mathrm{ZnO}$ nanorods. It has been found that process temperature of $90{ }^{\circ} \mathrm{C}$ displayed the highest photocatalytic efficiency and produced better array of $\mathrm{ZnO}$ nanorods as compared to other temperature level. It is due to the higher surface area generated on the sample [18]. 


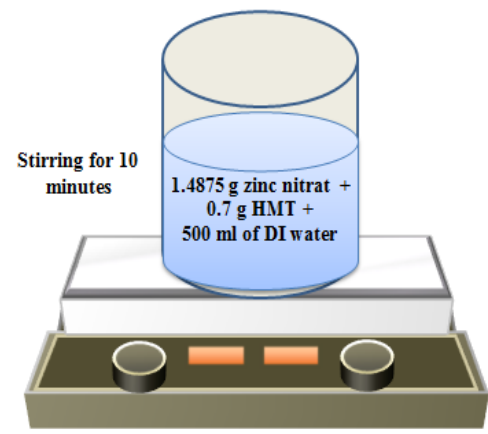

Figure 7. Preparation of $10 \mathrm{mM} \mathrm{ZnO}$ growth solution

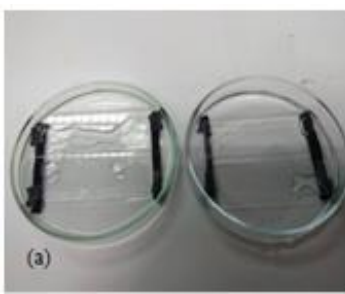

(a)

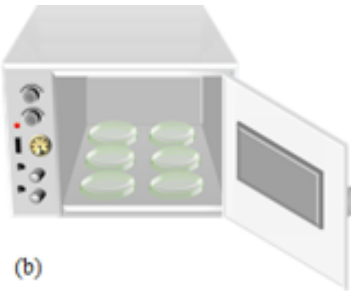

(b)

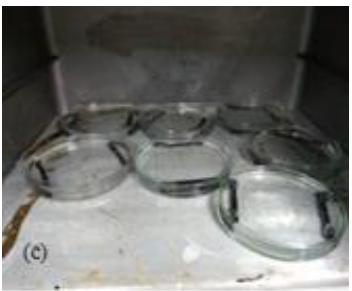

(c)

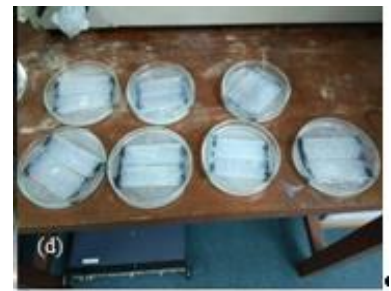

(d)

Figure 8. $\mathrm{ZnO}$ nanorods growth procedure; (a) seeded glass immerse in growth solution, (b) samples put in oven, (c) heated process in the oven and (d) $\mathrm{ZnO}$ nanorods coated glass at the end of the process

\section{RESULTS AND DISCUSSIONS}

The Hitachi model $3400 \mathrm{~N}$ was used to examine the morphology of $\mathrm{ZnO}$ nanorods growing on glass surfaces using field emission scanning electron microscopy (FESEM). Meanwhile, the chemical constituents of the samples were determined using energy dispersive X-ray (EDX). Figure 9 depicted the EDX elemental analysis of the coating samples consist of only zinc and oxygen [27]. Overall FESEM images of the nanorods on the glass surface at $5 \mathrm{kX}$ and $20.00 \mathrm{kX}$ magnifications using conventional synthesis process are shown in Figure 10(a) and (b). Where as FESEM images of the nanorods on the glass surface at $5 \mathrm{kX}$ and $20.00 \mathrm{kX}$ magnifications using optimum synthesis process are shown in Figure 11(a) and (b). It can be observed that $\mathrm{ZnO}$ nanorods morphological structures growth in aligned vertical direction as compared to the conventional process where the growth directed horizontally. It also shows that the density $\left(3 \times 10^{13}\right.$ nanorods $\left./ \mathrm{m}^{2}\right)$ of the optimum synthesis process improve by a factor of 2 as compared to the recent method [28]. The forward and backward scattering into the nanorods was affected by these physical structures, resulting in different light transmission behaviour inside the microfibre. As a result, the output light intensity would vary depending on the configuration of the nanorods.

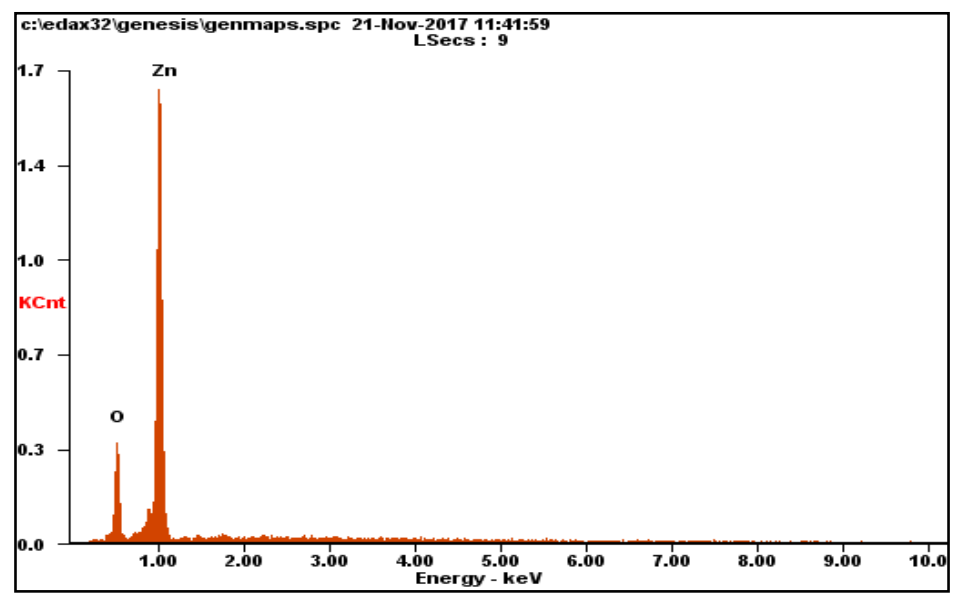

Figure 91. The samples solely contain zinc and oxygen, according to EDX elemental analysis 


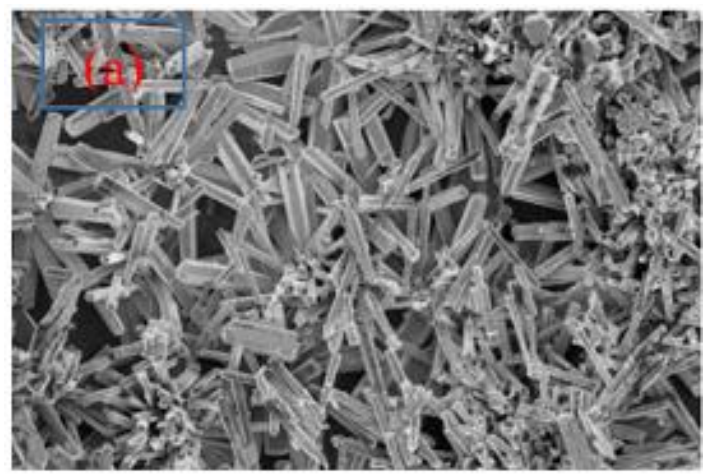

(a)

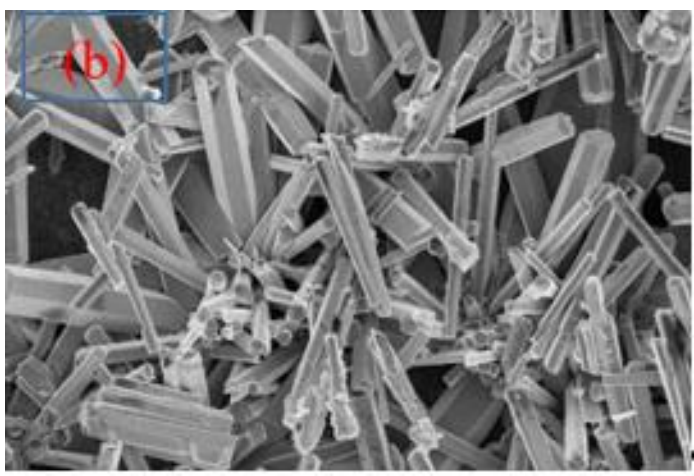

(b)

Figure 10. $\mathrm{ZnO}$ nanorods coated glass grow in horizontal direction using conventional synthesis process; (a) $5 \mathrm{kX}$ magnification and (b) $10 \mathrm{kX}$ magnification

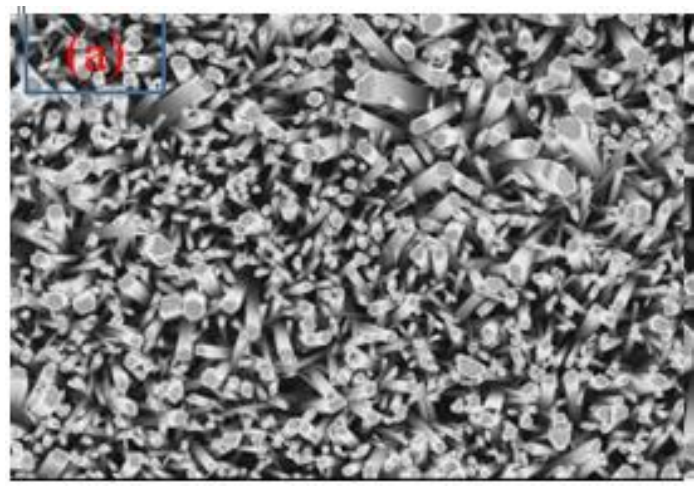

(a)

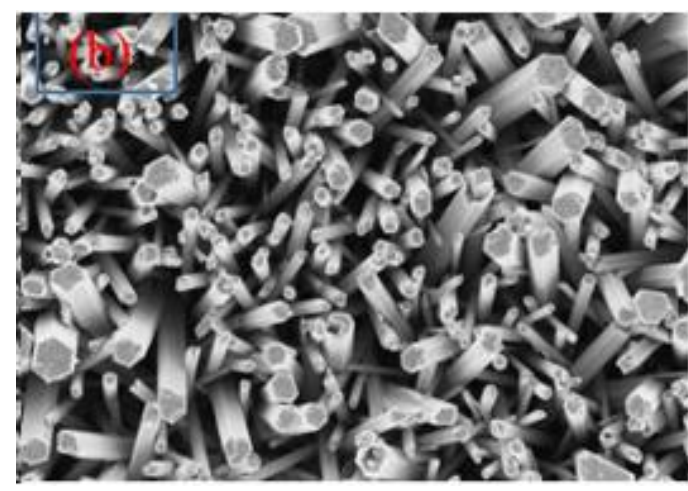

(b)

Figure 11. $\mathrm{ZnO}$ nanorods grow in uniform and vertically align with optimum synthesis process;

(a) $5 \mathrm{kX}$ magnification and (b) $10 \mathrm{kX}$ magnification

\section{CONCLUSIONS}

In summary, an optimum hydrothermal synthesis technique to grow aligned zinc oxide $(\mathrm{ZnO})$ nanorods vertically on the glass substrates has been successfully demonstrated. It is performed by employing optimized concentration alterations, growth duration, growth temperature and solvent variations. Based on the nanostructure characterization, the nanorods growth has been directed upwards vertically compared to the conventional process. This produced higher $\mathrm{ZnO}$ nanorods density up to $3 \times 10^{13}$ nanorods $/ \mathrm{m}^{2}$ which is double improvement as compared to conventional synthesis technique. It shows the optimum hydrothermal technique is effective to produce a good quality nanorods. Therefore, the work contributes to the investigation of the most optimum synthesis process to grow a well align $\mathrm{ZnO}$ nanorods which grow vertically and produce higher density of nanrods. Thus, for future research direction, the $\mathrm{ZnO}$ nanorods could be applied in variety integrated nano-systems such as resonators, medical devices, optoelectronics and RT gas sensor.

\section{ACKNOWLEDGEMENTS}

The authors would like to thank Universiti Teknikal Malaysia Melaka (UTeM) for the financial support.

\section{REFERENCES}

[1] L. M. Lechuga, "Optical sensors based on evanescent field sensing Part II. Integrated optical sensors," 2000.

[2] X. Sun, J. Huang, J. Wang, and Z. Xu, "A ZnO nanorod inorganic/organic heterostructure light-emitting diode emitting at 342 nm," Nano Letters, vol. 8, no. 4, pp. 1219-1223, 2008, doi: 10.1021/nl080340z.

[3] M. H. Jali, et al., "Formaldehyde sensor with enhanced performance using microsphere resonator-coupled $\mathrm{ZnO}$ nanorods coated glass," Optics \& Laser Technology, vol. 139, p. 106853, 2021, doi: 10.1016/j.optlastec.2020.106853. 
[4] H. H. M. Yusof, et al., "Detection of formaldehyde vapor using glass substrate coated with zinc oxide nanorods," IEEE Photonics Journal, vol. 11, no. 1, pp. 1-9, 2019, doi: 10.1109/JPHOT.2019.2895024.

[5] M. Alibakhshikenari, et al., "A Comprehensive Survey of "Metamaterial Transmission-Line Based Antennas: Design, Challenges, and Applications," IEEE Access, vol. 8, pp. 144778-144808, 2020, doi: 10.1109/ACCESS.2020.30136.

[6] M. Alibakhshi-Kenari, M. Naser-Moghadasi, R. A. Sadeghzadeh, B. S. Virdee, and E. Limiti, "A new planar broadband antenna based on meandered line loops for portable wireless communication devices," Radio Science, vol. 51, no. 7, pp. 1109-1117, 2016, doi: 10.1002/2016RS005973.

[7] M. Alibakhshi-Kenari, M. Naser-Moghadasi, and R. Sadeghzadeh, "The resonating MTM-based miniaturized antennas for wide-band RF-microwave systems," Microwave and Optical Technology Letters, vol. 57, no. 10, pp. 2339-2344, 2015, doi: 10.1002/mop.29328.

[8] D. Manisha, R. Merugu, A. Vijaybabu, and M. Pratap Rudra, "Microwave assisted biogenic synthesis of silver nanoparticles using dried seed extract of Coriandrum sativum, characterization and antimicrobial activity," International J. Chem. Tech. Res, vol. 6, pp. 3957-3961, 2014.

[9] Wang, Zhong Lin, "Zinc oxide nanostructures: growth, properties and applications," vol. 16, no. 25, p. R829, 2004, doi: 10.1088/0953-8984/16/25/R01.

[10] S. Hussain, et al., "A simple preparation of $\mathrm{ZnO}$ nanocones and exposure to formaldehyde," Materials Letters, vol. 128 , pp. 35-38, 2014, doi: 10.1016/j.matlet.2014.04.115.

[11] M. H. Jali, et al., "Optimization of sensing performance factor $(\gamma)$ based on microfiber-coupled $\mathrm{ZnO}$ nanorods humidity scheme," Optical Fiber Technology, vol. 52, p. 101983, 2019, doi: 10.1016/j.yofte.2019.101983.

[12] Baruah, Sunandan, Samir K Pal, and Joydeep Dutta, "Nanostructured zinc oxide for water treatment," vol. 2, no. 2, pp. 90-102, 2012, doi: 10.2174/2210681211202020090.

[13] D. Polsongkram, et al., "Effect of synthesis conditions on the growth of $\mathrm{ZnO}$ nanorods via hydrothermal method," vol. 403, pp. 3713-3717, 2008, doi: 10.1016/j.physb.2008.06.020.

[14] S. Baruah and J. Dutta, "Hydrothermal growth of $\mathrm{ZnO}$ nanostructures," Science and technology of advanced materials, vol. 10, p. 013001, 2009, doi: 10.1088/1468-6996/10/1/013001.

[15] C. J. Lin, S.-J. Liao, L.-C. Kao, and S. Y. H. Liou, "Photoelectrocatalytic activity of a hydrothermally grown branched Zno nanorod-array electrode for paracetamol degradation," Journal of hazardous materials, vol. 291, pp. 9-17, 2015, doi: 10.1016/j.jhazmat.2015.02.035.

[16] N.-F. Hsu, M. Chang, and K.-T. Hsu, "Rapid synthesis of $\mathrm{ZnO}$ dandelion-like nanostructures and their applications in humidity sensing and photocatalysis," Materials Science in Semiconductor Processing, vol. 21, pp. 200-205, 2014, doi: 10.1016/j.mssp.2013.09.019.

[17] R. Vequizo, M. Odarve, J. Gambe, and A. Alguno, "Growth of zinc oxide nanostructures on glass substrates for ethanol gas sensor application," in IOP Conference Series: Materials Science and Engineering, 2015, p. 012008, doi: 10.1088/1757-899X/79/1/012008.

[18] M. A. Mahmood, T. Bora, J. J. I. j. o. e. t. Dutta, and management, "Studies on hydrothermally synthesised zinc oxide nanorod arrays for their enhanced visible light photocatalysis," International journal of environmental technology and management, vol. 16, pp. 146-159, 2013, doi: 10.1504/IJETM.2013.050745.

[19] F. Z. Haque, N. Singh, P. Pandey, and M. R. Parra, "Study of zinc oxide nano/micro rods grown on ITO and glass substrates," Optik, vol. 124, no. 20, pp. 4167-4171, 2013, doi: 10.1016/j.ijleo.2012.12.052.

[20] N. A. Hambali, H. Yahaya, M. R. Mahmood, T. Terasako, and A. M. J. N. r. 1. Hashim, "Synthesis of zinc oxide nanostructures on graphene/glass substrate by electrochemical deposition: effects of current density and temperature," Nanoscale research letters, vol. 9, no. 1, p. 609, 2014, doi: 10.1186/1556-276X-9-609.

[21] C.-Y. Tsay, K.-S. Fan, Y.-W. Wang, C.-J. Chang, Y.-K. Tseng, and C.-K. J. C. I. Lin, "Transparent semiconductor zinc oxide thin films deposited on glass substrates by sol-gel process," Ceramics international, vol. 36, no. 6, pp. 1791-1795, 2010, doi: 10.1016/j.ceramint.2010.03.005.

[22] G. Amin, M. Asif, A. Zainelabdin, S. Zaman, O. Nur, and M. Willander, "Influence of pH, precursor concentration, growth time, and temperature on the morphology of $\mathrm{ZnO}$ nanostructures grown by the hydrothermal method," Journal of Nanomaterials, vol. 2011, 2011, doi: 10.1155/2011/269692.

[23] H. Zhang, D. Yang, X. Ma, Y. Ji, J. Xu, and D. J. N. Que, "Synthesis of flower-like ZnO nanostructures by an organic-free hydrothermal process," Nanotechnology, vol. 15, no. 5, p. 622, 2004, doi:

[24] M. H. Jali, et al., "Humidity sensing using microfiber-ZnO nanorods coated glass structure," Optik, vol. 238, p. 166715, 2021, doi: 10.1016/j.ijleo.2021.166715.

[25] A. A. Ismail, A. El-Midany, E. Abdel-Aal, and H. J. M. L. El-Shall, "Application of statistical design to optimize the preparation of $\mathrm{ZnO}$ nanoparticles via hydrothermal technique," Materials Letters, vol. 59, pp. 1924-1928, 2005, doi: $10.1016 /$ j.matlet.2005.02.027.

[26] A. Sugunan, et al., "Zinc oxide nanowires in chemical bath on seeded substrates: role of hexamine," Journal of SolGel Science and Technology, vol. 39, no. 1, pp. 49-56, 2006.

[27] M. H. Jali, H. R. A. Rahim, M. A. M. Johari, H. H. M. Yusof, B. Rahman, S. W. Harun, "Formaldehyde sensing using $\mathrm{ZnO}$ nanorods coated glass integrated with microfiber," Optics \& Laser Technology, vol. 120, p. 105750, 2019, doi: 10.1016/j.optlastec.2019.105750.

[28] M. H. Jali, H. R. A. Rahim, H. H. M. Yusof, M. A. M. Johari, S. Thokchom, and S. W. Harun, "Optimization of $\mathrm{ZnO}$ nanorods growth duration for humidity sensing application," in Journal of Physics: Conference Series, vol. 1371, no. 1, 2019, p. 012005, doi: 10.1088/1742-6596/1371/1/012005. 